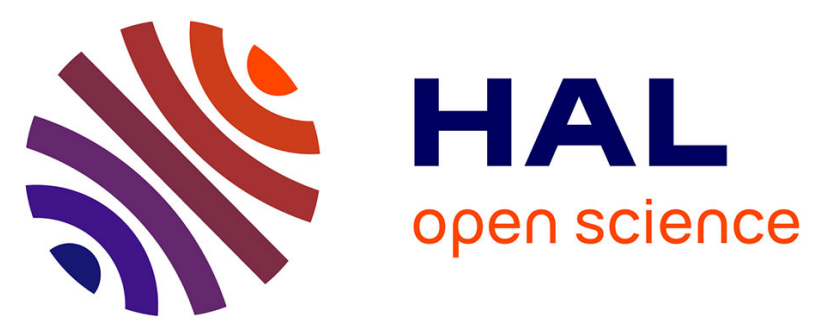

\title{
Towards Developing Interactive Content for Enhancing Life Skills Education in Tanzania: Possibilities and Pitfalls
}

\author{
Christian M. Budoya, Mussa M. Kissaka, Joel S. Mtebe
}

\section{To cite this version:}

Christian M. Budoya, Mussa M. Kissaka, Joel S. Mtebe. Towards Developing Interactive Content for Enhancing Life Skills Education in Tanzania: Possibilities and Pitfalls. 15th International Conference on Social Implications of Computers in Developing Countries (ICT4D), May 2019, Dar es Salaam, Tanzania. pp.374-385, 10.1007/978-3-030-19115-3_31. hal-02281321

\section{HAL Id: hal-02281321 \\ https://hal.inria.fr/hal-02281321}

Submitted on 9 Sep 2019

HAL is a multi-disciplinary open access archive for the deposit and dissemination of scientific research documents, whether they are published or not. The documents may come from teaching and research institutions in France or abroad, or from public or private research centers.
L'archive ouverte pluridisciplinaire HAL, est destinée au dépôt et à la diffusion de documents scientifiques de niveau recherche, publiés ou non, émanant des établissements d'enseignement et de recherche français ou étrangers, des laboratoires publics ou privés. 


\title{
Towards Developing Interactive Content for Enhancing Life Skills Education in Tanzania: Possibilities and Pitfalls
}

\author{
Christian M. Budoya ${ }^{1[0000-0003-4693-124]}$, Mussa M. Kissaka ${ }^{20000-0002-8607-7556]}$, \\ and Joel S. Mtebe ${ }^{3[0000-0003-2760-7673]}$ \\ University of Dar es Salaam, Tanzania \\ cbudoya@gmail.com, mkissaka@yahoo.com, and jmtebe@gmail.com
}

\begin{abstract}
Feasibility study is the first and important stage in any planning of introducing a new solution for overcoming existing challenges. It saves a lot of resources that could be lost if such solution fails to solve the intended problem. On the other hand, it gives a proper way to go ahead with the plan of introducing the solution. The purpose of this study is to establish necessary and basic requirements as possibilities and pitfalls for deploying cost effective interactive multimedia content for enhancing an ineffective provision life skills education at primary school level in Tanzania. Ten primary schools were randomly selected and surveyed from which 65 teachers and 407 pupils participated in the study. Questionnaires, interviews, and documentary reviews were used as data collection tools. It was found that the Internet penetration is $45 \%$ of the population with $82.6 \%$ of Internet users are smartphones users. Number of computers and tablets at schools are still limited to 1:1036 computer pupils ratio, $96 \%$ of pupils had access of computers and smartphones from parents. Moreover, $77 \%$ of teachers used conventional and lecturing style in teaching, $100 \%$ of life skills content was static found in inadequate textbooks. Based on these results, deployment of self-learning enabled interactive multimedia content is possible and will bring positive impact if it will be developed to operate in ICT devices available in both primary schools and pupils' parents as well. This study informs the proper way of introducing cost-effective interactive multimedia content at primary school level in Tanzania.
\end{abstract}

Keywords: Interactive multimedia content, Life skills education, Possibilities and pitfalls

\section{Introduction}

Interactive multimedia content has become a leading cost effective alternative in enhancing educational learning systems in recent years especially in a situation where ICT infrastructure is well established [15]. It can address a number of challenges such as lack of professional teachers by mimicking a best teacher when is well designed and [26], lack of teaching materials by providing learning materials with three modalities such as visual, oral and kinetic in which pupils learn better [26], and poor teaching methods by providing enhanced and augmented learning styles, more goals oriented learning, and more participatory by doing practically [26]. Flexible interactive 
content that can run in mobile platforms to support mobile life skills learning or offline standalone application is preferred more than others content in developing countries where ICT infrastructure is not yet well established [8].

Tanzania is one of the developing countries which have been adopting and introducing interactive content for a couple of years especially at higher learning institutions and secondary schools. Mtebe and Raphael [14] reviewed 74 e-learning articles carried out from 2007 to 2017 in Tanzania and it was found that 53 articles were for higher learning institutions, 16 for secondary schools, and only 2 for primary schools. The little interactive content studies at primary school level in Tanzania did not address the ineffective provision of life skills education in Tanzania.

Literature shows that life skills education for children has become a great concern due to its emphasis and effectiveness on promoting health, and meaningful social relationship [34, 16, 1]. It also empowers young people to take positive actions and protect themselves against various demands and challenges of everyday life [34, 16, 1]. Life skills education requires participatory teaching strategies such as classroom discussions, role playing, brainstorming, storytelling, debates, questions and answers, and educational games in order to impact pupils the required skills more effectively [22].

Tanzania introduced life skills education at primary school level to empower knowledge and prevent the pupils from challenges of everyday life such as smoking, alcoholism, use of drugs, sex abuse, school dropout and teenage pregnancies [22, 32, 18]. However, its implementation has not been effective since there is still alarming cases of life skills including among 3,797 pupils of primary schools, $95.8 \%$ used drugs, $91.2 \%$ used alcohol, $76.5 \%$ had sexual intercourse before age of 14 years and $27.1 \%$ missed classes for one or more days in 30 days [29]. The performance of pupils in the national standard four examinations of 2015 was poor in life skills topics especially Ethics and Humanity topic [17].

The lack of studies which can provide baseline data for introducing Interactive Multimedia Content at primary school level in Tanzania, has caused to conduct this study to bridge the gap. The results of this study will inform stakeholders the proper way of introducing cost effective interactive multimedia content in primary schools in Tanzania to enhance the provision of life skills education. Therefore, the aim of this study is to identify the challenges facing the implementation of life skills education in Tanzania and establish necessary basic requirements as possibilities and pitfalls for deploying appropriate interactive multimedia content.

\section{Literature Review}

Few studies are known about possibilities and pitfalls for deploying appropriate interactive multimedia content to enhance life skills education for primary school children in Tanzania. Some studies including Chacha [4], Machuve, Zlotnikova and Nyambo [11], Ntulo [19], Waddington [33], Enos [6], and Uwazi [31] pointed out in general the challenges facing primary education in Tanzania. Lack of professional teachers, poor teaching methods, large class sizes, inadequate teaching and learning materials were the challenges which have been affecting the quality provision of primary school education. For instance, Chacha [4] studied about challenges of primary education in 
Tarime district in Tanzania involving 6 teachers from two primary schools and 16 parents from two villages. Structured interviews and questionnaires were used to collect data. After data content analysis, the study discovered that very few teaching materials were available in percentage including teacher guide books was $17.6 \%$, chalks were $31 \%$, library and laboratory was $0 \%$, Pupils' textbook was $10.7 \%$, extra books available was $0 \%$, and poor parents were not able to buy textbooks for their children.

Limited studies about status of ICT infrastructure in primary schools were also found including Apiola and Tedre [2], Komba [10], and Hennessy and co-authors [8]. These studies revealed that ICT initiatives in primary schools is still constrained by unavailable electricity supply, inadequate ICT equipment leading to overcrowding of computer labs, insufficient and inappropriate software including software designed for Northern contexts or languages, unaffordable access to Internet connectivity with adequate bandwidth, lack of trained teachers and the low levels of teachers' ICT knowledge and skills. Although, ICT curriculum for discrete subject/TEHAMA had been introduced at primary level in Tanzania [8], pupils were taught basic computer skills and not how to use ICT as a tool to enhance learning [8]. The language of instruction in primary schools in Tanzania is Kiswahili which constitutes less than 2\% of the Internet content. Therefore, ICT-based Kiswahili content is needed.

Other studies such as by Apiola and Tedre [2], Machuve and co-author [11], and Kasumuni [9] designed various interactive content for enhancing learning including mobile applications, online games, e-books, and delivering video by mobile in classrooms. After testing their effectiveness, most of them motivated the pupils to learn and pupils' academic performances were improved. Moreover, Preradović and co-authors [23], Shegog and co-author [26], Dolhalit and Salam [5], Hafiz and Ahmad [7], and Rath and coauthors [24] applied interactive content to impact the children with the preventive life skills education to eradicate various life skills cases including HIV/ STI, early pregnancy, smoking, truancy and stress. Altitude against the life skills cases were enhanced and therefore interactive multimedia has significant effect on student's motivation and can remove bad behaviors among children.

All these studies have never studied about challenges faced provision of life skills education and possibilities and pitfalls for deploying interactive content to enhance provision of life skills education at primary school level in Tanzania. So far, it remains unclear about the challenges faced provision of life skills education, status of ICT infrastructure, and others possibilities and pitfalls for deploying interactive content in primary schools in Tanzania. Therefore, this study is aimed at bridging this gap.

\section{Methodology}

\subsection{Research Design}

Survey study was conducted in 10 primary schools involving 65 life skills teachers, and 407 standard five pupils who recently passed standard four national examinations. Various data were collected through questionnaires, interviews, and documentary reviews and they were analyzed using content and statistical analysis. The problems faced the provision of life skills education were identified. The identified problems 
which can be addressed by deployment of interactive multimedia content were termed as possibilities while the identified problems which hinder the deployment of interactive multimedia content were termed as pitfalls. The factors which support operationalization of interactive multimedia content were identified as possibilities and those which do not support operationalization of interactive multimedia content were identified as pitfalls.

\subsection{Participants}

Sixty five teachers and 407 pupils participated from 10 primary schools in this study. There were two types questionnaires for teachers, one for school administrators who are head teachers for collecting administration based data and the second questionnaire was for teachers who teach life skills subjects for data such as teaching methods and challenging life skills topics. The number of female teachers who participated in the study was large compared to male teachers since the majority of teachers in the schools were females. The distribution of the teachers who participated is shown in Fig. 1.

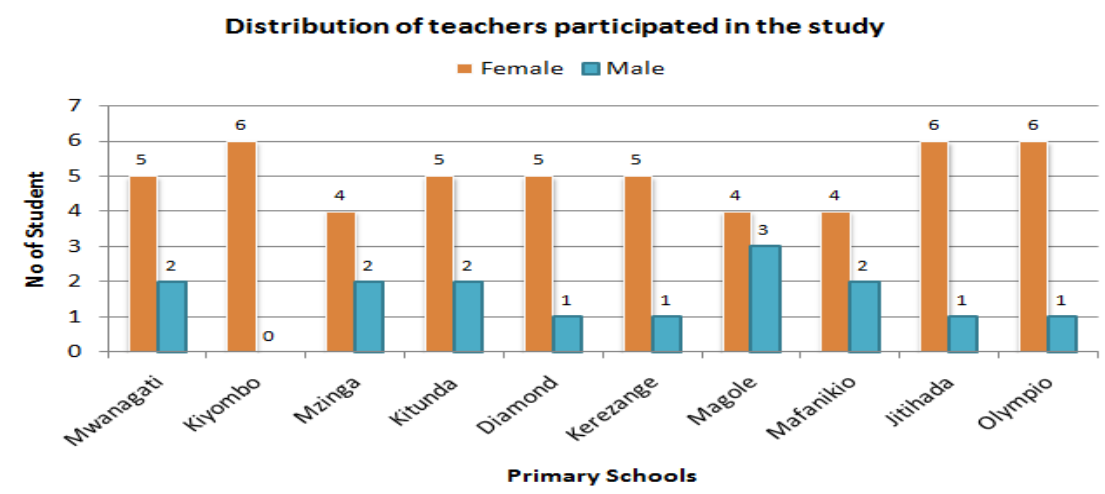

Fig. 1. Distribution of Participated Teachers per School

The distribution of the pupils from 10 primary schools who participated in this study is shown in Fig. 2. The female pupils who participated in the study is large compared to male pupils since almost all 10 primary schools which were surveyed had many females enrolled compared to number of males. 


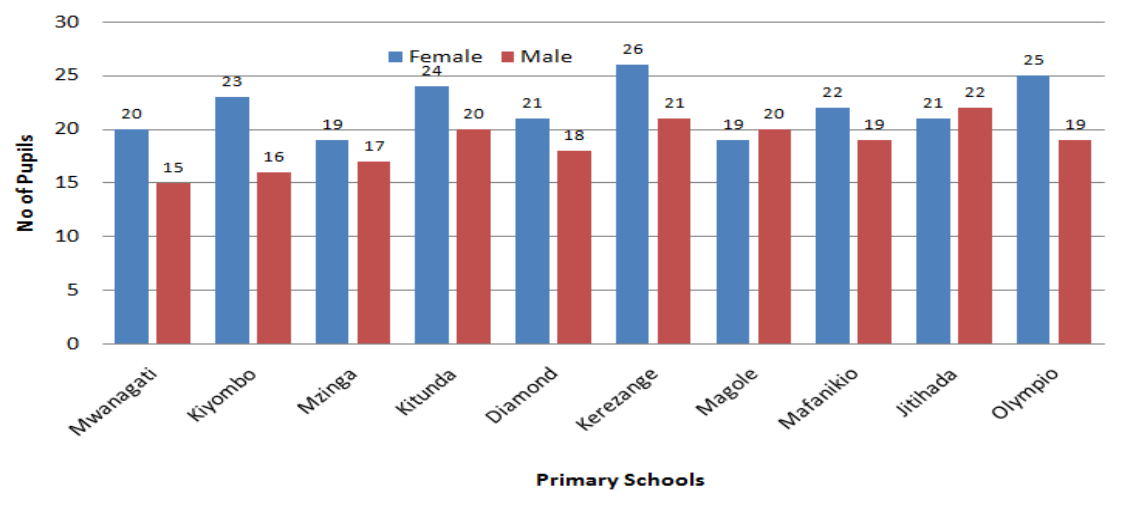

Fig. 1. Distribution of Pupils Participated in the Study

\subsection{Data analysis}

Quantitative data from head teachers, life skills teachers, and pupils were analyzed using Microsoft Excel Program 2010. Descriptive, computed, and comparison statistics were used in data analysis, the collected data were edited, coded, and translated from Kiswahili to English. Tables were used to summarize the results from which graphs were drawn. Qualitative data which were collected through open-ended questions and interviews were gathered, summarized and subjected to content analysis.

\section{Findings}

\subsection{Possibilities}

In this study, many factors were found supporting and demanding the possibility of enhancing life skills education using interactive content. The supporting factors were availability of ICT infrastructure, experience of pupils in learning through computer based games and video based storytelling cartoons, and availability of electricity in schools. While the demanding factors were lack of professional teacher, lack of teaching materials, and poor teaching methods.

Availability of computer laboratories: It was observed that three primary schools had computer laboratories out of ten primary schools. The rest of primary schools had only one computer used by head teacher for examinations preparation. According to National Basic Education Statistics in Tanzania (BEST), there were 8,334 computers, laptops and smartphones and 8,639,202 pupils from 17,174 primary schools equivalent to 1:1036 computer pupils ratio [3]. The Internet penetration has been increasing from 29\% in 2014 to $40 \%$ in 2016 and $45 \%$ in 2018 while mobile phone penetration has increased from $80 \%$ in 2016 to $82.6 \% 2018$ of the total Internet users [27, 28]. Out of 17,174 primary schools, 3,818 use national grid electric power, 262 use gener- 
ators, 1295 use solar, 18 use biogas, and 14 use wind, 9,376 use others, and 2,502 have no electricity [3]. Therefore, $85 \%$ of primary schools had electricity. This is one of the factors support operationalization of the interactive multimedia content in primary schools.

Pupils' access and use of computers and mobile devices: Pupils were interviewed to find out if they were using computers and smartphones in playing games or watching entertaining video from their parents' devices. After analyzing the data, it was found that $96 \%$ of pupils were playing games at home using their parents' smartphones and computers. Other pupils used to go to computer games business centers where they pay some money and played various games. For pupils whom their parents did not have smartphones and computers used their neighbor pupils' parents' devices as shown Fig. 3. This factor is considered as an opportunity for deploying interactive content in pupils' parents' devices where the pupils could be able to access the interactive content for life skills education.

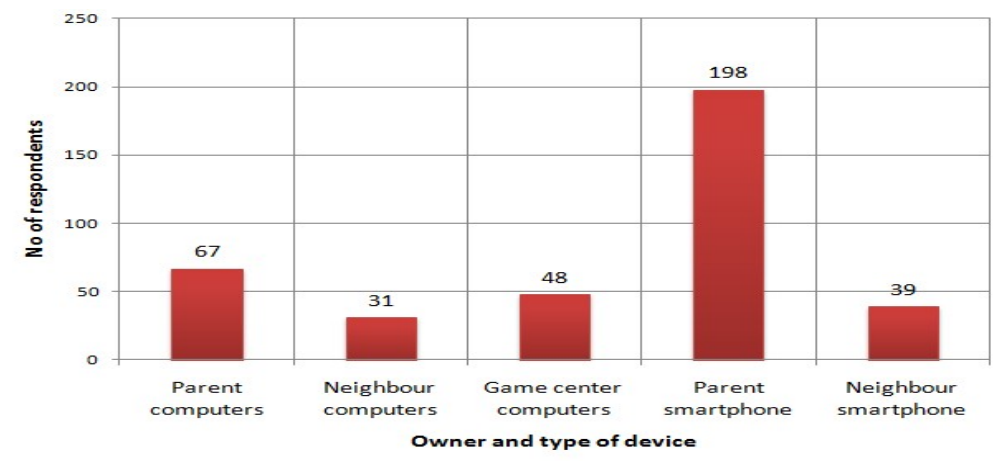

Fig. 1. Pupils Playing Games Using Smartphones and Computers

Mobile life skills learning: It was also found that about $58 \%$ pupils had access to smartphones, 96\% had access to both smartphones and computers (see Fig. 3) and 82.6\% of Internet users are smartphones users [28]. With these facts, mobile life skills learning is possible especially when the interactive content is developed to run in smartphone. The primary school education policy does not allow pupils to own and use any phone at school. Therefore, the mobile devices owned by schools and parents will be used at schools and at home respectively. This is another factor which supports deployment of interactive content.

Challenging life skills topics in teaching the pupils: The pupils and teachers were requested to mention any challenging life skills topics which demand practical knowledge. The challenging life skills topics which were mentioned by the teachers and pupils were Health Care, Communication, Relationship and Cooperation, Road Safety, Problems and Risk Behaviors, Critical Thoughts, Good Decisions and Plans, and Ethics and Humanity. The Fig. 4 shows that both pupils and teachers mentioned similar challenging life skills topics and the most challenging topics were Road Safety 
and Ethics and Humanity. This is another factor which demands deployment of interactive content

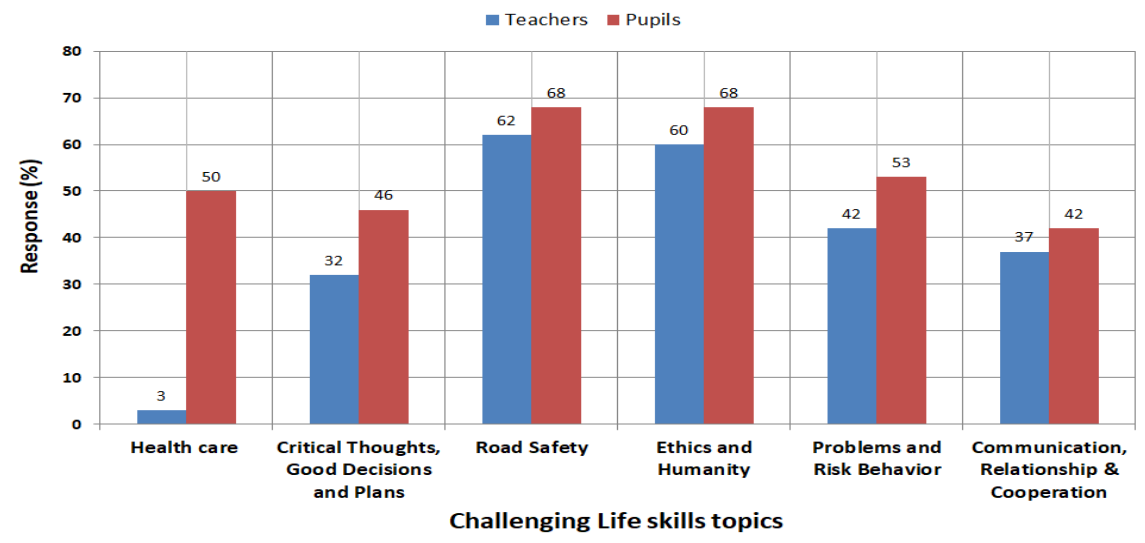

Fig. 1. Teachers and Pupils Responses (\%) for Identifying Challenging Life Skills Topics

Lack of professional teachers, and teaching and learning materials: Head teachers from every primary school were asked to assess availability of professional teachers and teaching materials in their schools. After analyzing the data, it was found that most of primary schools lacked professional teachers who can teach life skills especially in public schools which their deficit ranges from 4 to 15 teachers per school except Mzinga private school which had enough teachers and textbooks (see Table 1). There were deficits of teaching and learning materials for life skills including textbooks, practical and demonstration equipment, and interactive content. In public schools, some of classes did not have even a single textbook for pupils while other schools shared one textbook for 5 to 20 pupils. Interactive content is also not available at all in all schools. This is also another challenge which demands deployment of interactive content.

Table 1. Deficits of Teaching Materials and Teachers per Life skills Subjects

\begin{tabular}{|c|c|c|c|c|c|c|c|c|c|}
\hline \multirow{3}{*}{$\begin{array}{l}\text { S/ } \\
\mathrm{N}\end{array}$} & \multirow{3}{*}{$\begin{array}{l}\text { Name of Pri- } \\
\text { mary School }\end{array}$} & \multicolumn{8}{|c|}{ Life Skills Subjects ( Learning Materils and Teachers deficits) } \\
\hline & & \multicolumn{2}{|c|}{ Science } & \multicolumn{2}{|c|}{ TEHAMA } & \multicolumn{2}{|c|}{ Personality \& Sports } & \multicolumn{2}{|c|}{ Civis } \\
\hline & & 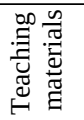 & 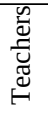 & 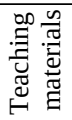 & 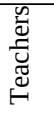 & 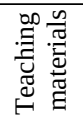 & 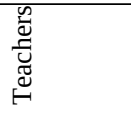 & 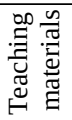 & 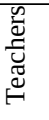 \\
\hline 1 & Mwanagati & 258 & 3 & 892 & 3 & 921 & 3 & 844 & 3 \\
\hline 2 & Kiyombo & 590 & 5 & 801 & 5 & 801 & 4 & 590 & 4 \\
\hline 3 & Mzinga (Private) & 0 & 0 & 0 & 0 & 0 & 0 & 0 & 0 \\
\hline 4 & Kitunda & 1251 & 10 & 1238 & 10 & 1236 & 10 & 1225 & 10 \\
\hline 5 & Diamond & 1280 & 2 & 1284 & 3 & 1284 & 3 & 1283 & 5 \\
\hline 6 & Kerezange & 966 & 6 & 1050 & 5 & 1093 & 4 & 926 & 7 \\
\hline
\end{tabular}




\begin{tabular}{|l|l|c|c|c|c|c|c|c|c|}
\hline 7 & Magole & 511 & 2 & 779 & 3 & 784 & 3 & 698 & 2 \\
\hline 8 & Mafanikio & 466 & 5 & 778 & 6 & 777 & 4 & 553 & 11 \\
\hline 9 & Jitihada & 1154 & 5 & 1410 & 6 & 1381 & 5 & 1422 & 4 \\
\hline 10 & Olympio & 2095 & 14 & 2098 & 12 & 2100 & 12 & 2088 & 15 \\
\hline
\end{tabular}

Teaching and learning methods: Pupils and teachers were asked to mention and explain the methods they were using in teaching and learning life skills. After collecting and analyzing the data, it was found that both teachers and pupils agreed that conventional and traditional method of teaching and learning that is lecturing style was frequently used which depends heavily on memorization, definition, and knowledge of facts and concepts [20] (see Fig. 5). Conventional methods cannot reinforce creative and critical thinking among pupils and they are slow in transferring learning content since pupils do not participate effectively $[23,20]$. This is also another challenge which demands deployment of interactive content that can include various teaching and learning methods especially practical, demonstrations, and simulations which provides active learning.

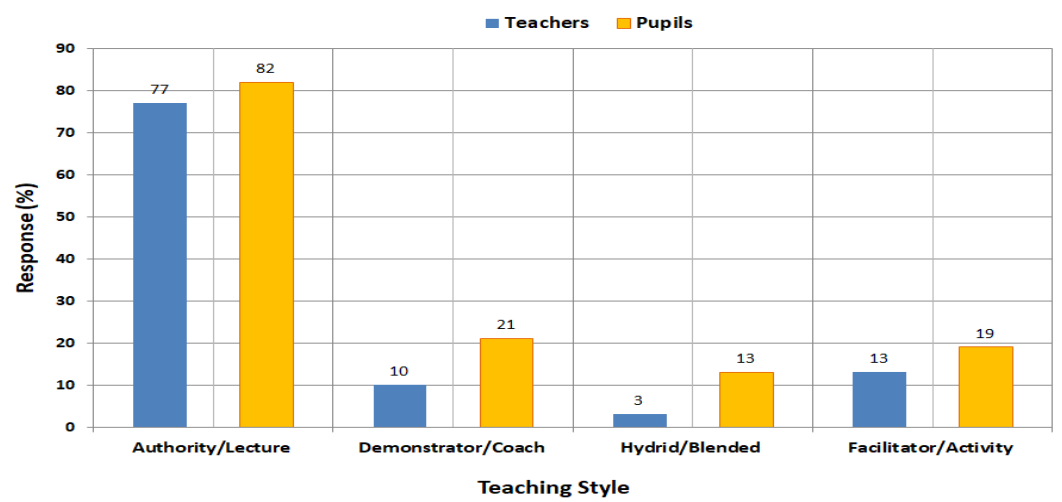

Fig. 1. Teachers and Pupils Responses (\%) for Identifying Teaching Styles Used

\subsection{Pitfalls}

There are challenges that can hinder the deployment of interactive content for enhancing life skills education for children include inadequate ICT computing devices, large number of pupils in classrooms, short period time of learning, and lack of ICT knowledge among the teachers

Inadequate ICT computing devices at schools: Inadequate of ICT computing devices at school is the major obstacle for operationalization of the interactive content. In this survey it was found that there were limited number of ICT devices in the schools such as computers, tablets, smartphones and laptops. However, Mzinga private school had computer laboratory with 12 desktop computers and two public schools which each of them had 144 tablets. The rest had one computer per school. 
The ICT devices available at schools and owned by pupils' parents should be considered to address this challenge.

Large number of pupils in classrooms: The head teachers from every primary school were also asked to provide student enrolment data especially the number of streams per class. After data analysis, it was found that most of classes had 2 to 4 streams per class and each stream has pupils from 70 to 150 pupils. This range is very large compared to the standard which is 45 pupils [12, 30]. It is difficult for a teacher to teach, assess and supervise regularly many pupils in a session of 40 minutes according to curriculum of 2005 and 2016 [12, 30]. This is another challenge that can be addressed by considering the ICT devices available at schools and owned by pupils' parents and the interactive content should be self-learning enabled.

Lack of ICT trained teachers: The primary schools teachers who teach life skills were interviewed to see whether they got any ICT in-service training to upgrade their ICT skills. It was found that most teachers had never received any ICT training even if the curriculum of 2005 introduced TEHAMA/ICT subject [12, 30]. Therefore, the primary school teachers lack ICT knowledge which is needed in order to support the operationalization of interactive content at schools. To address this challenge, the ICT devices available at schools and owned by pupils' parents should be used and the interactive content should be self-learning enabled.

\section{Discussion}

The aim of this study was to identify challenges faced implementation of life skills education for primary school children in Tanzania and establish basic requirements as possibilities and pitfalls for deploying interactive multimedia content. Life skills education was introduced to prevent a wide range of life skills challenges faced the primary school children such as smoking, alcoholism, use of drugs, sex abuse, school dropout and teenage pregnancies [31]. The current alarming cases of life skills in Tanzania including among 3,797 pupils of primary schools $95.8 \%$ used drugs, $91.2 \%$ used alcohol, $76.5 \%$ had sexual intercourse before age of 14 years and $27.1 \%$ missed classes for one or more days in 30 days [29] proved that the implementation of life skills education was not effective. The cost effective means of enhancing provision of life skills education is through deploying interactive content [26]. Lack of studies to provide basic information as possibilities and pitfalls for deploying interactive multimedia content created a need of conducting this study and many possibilities and pitfalls were found after surveying the 10 primary schools.

It was found that most of schools lacked professional teachers who can teach the children life skills especially in public schools where deficit ranges from 4 to 12 teachers per school. The increase of enrolment of pupils after free education declaration in 2015 caused increase of 2 to 4 streams per class, each and every stream ranges from 70 to 150 pupils. These results is exactly equal to that at national level which is 1:77 Pupil Classroom Ratio (PCR) and at Dar es salaam region is 1:102 while the standard is 1:45 [3]. It is difficult to teach large classes, assess and supervise every in- 
dividual pupil. It is possible for individual pupil to learn frequently using self-learning enabled interactive content installed in both schools' computers and smartphones and parents' smartphones to complement the lack of professional teacher at low cost [26].

It was also very interesting to find out that the challenging life skills topics selected by pupils were the same with those selected by teachers after they were compared (see Fig. 4). This results of comparison proved that the selected life skills topics are real challenging and they are the same topics in which the pupils poorly performed in the national examination for standard four in 2015[17]. These topics demand deployment of interactive content which can provide practical knowledge rather than theoretical teaching and learning [26].

Lack of teaching and learning materials including textbooks, practical and demonstration equipment, and interactive content is another finding especially in public schools. Some of classes did not have even single textbook for pupils, while in other schools there were 5 to 10 pupils shared one textbook. In Dar es salaam region the Pupil Textbook Ratio (PBR) ranges from 1:0 to 307:1 while the standard is 1:1 [21]. This is the same as what was reported by other studies $[4,11,19,33,6]$. This challenge demands deployment of interactive content which can serve as textbooks at low cost [26].

Another interesting finding was the teaching and learning methods mentioned by teachers were the same with those mentioned by pupils and both of them highlighted the lecturing style was applied at the rate of $77 \%$ and $82 \%$ respectively (see Fig. 5) The lecturing style does not provide active learning contrary to curriculum setting [12, 30] and life skills teaching requirement which needs participatory methods[1]. Having similar results after comparing the two different groups proved the existence of such challenge which is also supported by the studies $[4,11,19,33,6]$. This is a challenge which demands deployment of interactive content that can provide active learning [26].

It was also found that the ICT resources including computer, laptops, tablets, and smartphones at primary schools were inadequate especially in public schools where only two out of ten schools had 144 smartphones. At the national level the pupil computer ratio is 1056 pupils per one computer (1056:1) which is a major pitfall that limits the deployment of interactive content [3]. On the other hand, 96\% of pupils had access of computer, laptops, tablets, and smartphones from their parents and according [28] there are 19,006,223(82.6\%) mobile smartphones access Internet. Other pitfalls are large number of pupils and lack of ICT trained teachers. To address these challenges, both ICT devices available at schools and owned by pupils' parents should be used and the interactive content should be self-learning enabled.

Other important ICT resources which were found are availability of Internet connection, and electricity in which all primary schools had mobile wireless Internet while two of them had fixed wireless internet and according to [28] the increase of Internet penetration has reached $45 \%(22,995,109)$ of national population. This is very important resource for operational of interactive content. Moreover, all ten primary schools had electricity and according to [3], 85\% of primary schools have electricity. Therefore, this is another important factor to power ICT computing devices for running the interactive content. 


\section{Conclusion}

This study tried to find out the feasibility of deploying interactive multimedia content for improving quality of provision of life skills education at primary school level in Tanzania. The findings such as availability of Internet, availability of electricity, pupils's access of ICT computing devices owned by their parents, availability of learning challenges that needs interactive multimedia content including lack of professional teachers, lack of teaching and learning materials and poor teaching methods have proved that it is possible to deploy interactive multimedia content. The challenges such as limited number of ICT computing devices at primary schools is addressed by the presence of ICT mobile devices owned by their parents. While the large number of pupils in classrooms and lack of ICT trained teachers can be addressed by deploying self-learning enabled interactive content. Therefore, this study recommends that in order to enhance life skills education and bring positive impact in primary schools in Tanzania, self-learning enabled interactive multimedia content should be designed and deployed in ICT computing devices owned by both primary schools and pupils' parents. Further study is needed on how the self-learning enabled interactive multimedia content will be designed and tested to see its effectiveness.

\section{References}

1. Aparna, N., \& Raakhee, A. S.: Life skills education for adolescents: Its relevance and importance. Education Science and Psychology, 2(2), 3-7 (2011).

2. Apiola, M., \& Tedre, M.: Pedagogical Outlines for OLPC Initiatives : A Case of Ukombozi School in Tanzania, (November 2010), 13-15 (2011).

3. BEST.: National Basic Education Statistics in Tanzania (BEST), 2012-2016 (2016).

4. Chacha, G.: The Challenges of Primary Education Level in Tanzania ., 16(3), 1-6 (2013).

5. Dolhalit, M. L., \& Salam, S. N. A.: Exploring Persuasive Multimedia Techniques in Attitude and Behavior Change: A Comparative Study. Procedia - Social and Behavioral Sciences, 155(October), 386-391. https://doi.org/10.1016/j.sbspro.2014.10.310 (2014).

6. Enos, N.: Practices and Challenges in the Provision of Pre-Primary Education in Tanzania, 10(40), 1-16 (2016).

7. Hafiz, M., \& Ahmad, S. Z.: Smoke Shooter : Introducing Danger of Smoking to School Children with Persuasive Technology, 686-690 (2012).

8. Hennessy, S., Onguko, B., Harrison, D., Kiforo, E., Namalefe, S., \& Naseem, A.: Developing the Use of Information and Communication Technology to Enhance Teaching and Learning in East African Schools: Review of the Literature. Africa, (May), 121. https://doi.org/10.1017/ gmh.2015.5 (2010).

9. Kasumuni, L.: Delivering video by mobile phone to classrooms in Tanzania. Retrieved from https://ela-newsportal.com/delivering-video-by-mobile-phone-to-classrooms-in-tanzania (2011).

10. Komba, S. C.: The use of computers by primary school pupils in Morogoro , Tanzania The use of computers by primary school pupils in, (February). https://doi.org/10.5861/ ijrset.2016.1431 (2016).

11. Machuve, D. Z., Zlotnikova, I., \& Nyambo, D.: Monitoring and Evaluation of the E-readers Project in Rural Tanzania, 62-67 (2014). 
12. MoEST.: Basic education curriculum standard III-VI. https://doi.org/ 10.1787/9789264177949-147-en (2016).

13. Mruz, K.: 2011 Rwanda TeacherMate Report (2011).

14. Mtebe, J. S., \& Raphael, C.: A critical review of eLearning research trends in Tanzania. Journal of Learning for Development, 5(2), 163-178 (2018).

15. Mugo, R.: Schools - Use of ICTs • Global \& Regional Perspective • Policy and Legal • Conclusion Framework (2017).

16. Mwangi, L. I.: Effectiveness of Implementing Life Skills Curriculum in Primary Schools in Murang'a East Sub-County, Murang'a County, Kenya (2015).

17. NECTA.: Pupils ' Items Response Analysis Report In Development and Sports (2015).

18. NLSEF.: National Life Skills Education Framework, (December). Retrieved from www.moevt.org (2010).

19. Ntulo, V. P.: challenges in primary schools (2015).

20. Nusir, S., Jordan, I., Jordan, I., Al-kabi, M., Jordan, I., \& Jordan, A.: Designing an Interactive Multimedia Learning System for Primary School Children in Jordan, 45-51(2011).

21. PBRPrimary.: The United Republic of Tanzania - Government Basic Statistics Portal. Retrieved from http://opendata.go.tz/en/dataset/pbr-primary-education-2018 (2018).

22. Prajapati, R., Sharma, B., \& Sharma, D.: Significance Of Life Skills Education. Contemporary Issues in Education Research, 10(1), 1-6 (2017).

23. Preradović, N. M., Unić, D., \& Boras, D.: Preschool and Primary School Children as Multimedia Learners, 8 (2014).

24. Rath, J. M., Williams, V., Rubenstein, R., Smith, L., \& Vallone, D.: Assessing the Impact of an Interactive Mobile Game on Tobacco-Related Attitudes and Beliefs: Games for Health Journal, 4(6), 480-487. https://doi.org/10.1089/g4h.2015.0005 (2015).

25. Reddi, U. V., Saxena, A., Anita Dighe, Parhar, M., Mishra, S., Rao, A. S., ... Ramanujam, P. R.: A Handbook for Teacher-Developers (2003).

26. Shegog, R., Markham, C., Peskin, M., Dancel, M., Coton, C., \& Tortolero, S.: "It’s Your Game": An Innovative Multimedia Virtual World to Prevent HIV/STI and Pregnancy in Middle School Youth. Studies in Health Technology and Informatics, 129(Pt 2), 983-987. Retrieved from http://www.ncbi.nlm.nih.gov/pubmed/17911862 (2007).

27. TCRA.: Tanzania Communication Regulatory Authority-April- June 2017 Quarter. TCRA,Reports, 2(June), pp.1-18 (2017).

28. TCRA.: Tanzania Communication Regulatory Authority quarterly communication statistics report: April - June 2018, (JUNE). Retrieved from https://www.tcra.go.tz/images/documents/ reports/TelCom_Statistics_June_2018.pdf (2018).

29. TGSHS.: Tanzania Mainland Global School based S tudent Health Survey, (May) (2017).

30. TIE.: Mtaala wa Elimu ya Msingi Tanzania (2005).

31. Uwazi.: Primary schools in Dar es Salaam : Overcrowded and without sufficient text books, (3), 1-4 (2011).

32. Vranda, M., \& Rao, M.: Life Skills Education for Young Adolescents-Indian Experience. Jiaap.Org, 37(Special Issue), 9-15. Retrieved from http://www.jiaap.org/Listing_Detail/Logo/ 95d5717c-572f-483d-a807-a69139ef8c53.pdf (2011).

33. Waddington, J.: IKnowledge (Tanzania) Monitoring And Evaluation Mid Term Report, (1111283), 1-84 (2016).

34. WHO.: World Health Organization-Life skills education in schools. World Health, 132-148. Retrieved from www.who.int (1997). 